\title{
DA CONSCIÊNCIA À PRÁTICA: HÁBITOS DE LEITURA DE ALUNOS DO ENSINO MÉDIO DO IFRS - CAMPUS FARROUPILHA
}

\author{
Cecil Jeanine Albert Zinani* \\ Cinara Fontana Triches ${ }^{* *}$
}

\begin{abstract}
Resumo: Este artigo tem como intuito analisar os hábitos de leitura dos alunos do curso Técnico em Informática Integrado ao Ensino Médio do IFRS - campus Farroupilha, a partir de dados obtidos em uma pesquisa realizada em 2014. Por meio de um recorte nos resultados obtidos, objetiva-se verificar a relação com a leitura, as influências, além de gostos e hábitos dos adolescentes. Como um dos resultados expressivos, fica evidente a influência do incentivo dos pais sobre o posicionamento quanto à prática da leitura. Ademais, há o reconhecimento da influência das redes sociais nos hábitos de leitura. A partir dos resultados, é possível reforçar a importância de que o docente conheça o perfil do aluno, para que possa atuar como mediador de leitura.
\end{abstract}

Palavras-chave: Hábitos de leitura. Influências. Adolescentes.

\begin{abstract}
This article aims to analyze the reading habits of students of the Computer Technical Course Integrated to High School from IFRS - campus Farroupilha, from data obtained in a research conducted in 2014. Through an extract of the results, the objective is to verify the relationship with the reading, the influences, besides the preferences and habits of the adolescents. As one of the expressive results, the influence of the parents' incentive on the positioning of reading practice is evident. In addition, there is the recognition of the influence of social networks on reading habits. From the results, it is possible to reinforce the importance of the teacher knowing the profile of the student, so that he can act as a mediator of reading process.
\end{abstract}

Keywords: Reading habits. Influences. Adolescents.

\section{Introdução}

A leitura, um complexo processo de interação entre texto e leitor, é um dos principais tópicos de discussão no ambiente escolar. Isso porque ela é um instrumento necessário para a realização de novas aprendizagens (SOLÉ, 1998), razão pela qual tornar os alunos leitores ativos - que compreendem o que leem e constroem o significado do texto a partir da finalidade de sua leitura - é um dos principais objetivos da educação básica. Pode-se observar tal concepção nos Parâmetros Curriculares Nacionais (PCNs), no qual leitura

[...] é um processo no qual o leitor realiza um trabalho ativo de construção do significado do texto, a partir de seus objetivos, do seu conhecimento sobre o assunto [...] não se trata simplesmente de extrair informações da escrita, decodificando-a letra por letra, palavra por palavra. Trata-se de uma atividade que implica, necessariamente, compreensão. (BRASIL,1998, p.41).

Junto a isso, os PCNs também abordam a leitura de obras literárias no Ensino

\footnotetext{
*Doutora em Letras (UFRGS); Estágio de Pós-Doutoramento em Memória e História (PUCRS). Professora e Pesquisadora no Curso de Letras e nos Programas de Pós-Graduação PPGLET da Universidade de Caxias do Sul e PDLET Associação Ampla UCS-UNIRITTER. cezinani@ @erra.com.br.

** Mestre em Letras e Cultura Regional pela Universidade de Caxias do Sul (UCS). Doutoranda em Letras no Programa de Pós-Graduação em Letras da UCS. Docente da área de Letras do Instituto Federal de Educação, Ciência e Tecnologia do Rio Grande do Sul, campus Farroupilha. cinara.triches@ farroupilha.ifrs.edu.br
} 
Médio, elencando as teorias de Michail Bakhtin, Roland Barthes e Umberto Eco para destacar sua múltipla possibilidade de significados, devido ao importante papel de significação do leitor frente ao texto. Através dos conceitos de Eco (1998 e 2003), o documento aborda dois tipos de leitores: o vítima, refém do enunciado; e o crítico, interessado em entender como se tornou vítima do enunciado, ou seja, em entender as formas de narrar. Este último é o leitor que a escola deve formar, razão pela qual a prática da metaleitura deve ser evitada, já que

[...] tais atividades não consistem em fazer com que os jovens leiam, mas em fazê-los refletir sobre os diversos aspectos da escrita: organização da língua, história literária dos textos, estrutura dos textos literários, etc. Todavia, quando os jovens não são ainda leitores (na nossa escola, é essa a situação da maior parte dos alunos), é difícil fazê-los se interessarem por atividades de metaleitura, além do que, se não leram os textos, o trabalho apresenta-se inteiramente inútil, resultando em desinteresse não só pelas atividades como pela própria leitura do texto, a qual lhes parecerá apenas um pretexto para realizar exercícios enfadonhos. (BRASIL, 1998, p. 42).

A partir disso, os PCNs preconizam o papel do docente como mediador da leitura, na seleção das obras - não privilegiando apenas a literatura brasileira, mas utilizando seu conhecimento e fruição para proporcionar leituras do cânone que levem seus alunos a uma leitura significativa - e na criação de estratégias para fomentá-la.

É fato o papel do professor no incentivo à leitura. Sem considerar questões referentes à sua formação e, inclusive, a seus hábitos de leitura, parece essencial que o docente saiba quem é seu aluno para que consiga desempenhar de forma relevante seu papel como mediador.

A partir desses pressupostos, pretende-se analisar alguns dados sobre a relação dos alunos adolescentes com a leitura, o que influencia esse hábito e como é o habito da leitura, além de seus gostos. Os dados foram obtidos por meio de pesquisa para um trabalho de conclusão de curso de uma aluna ${ }^{2}$ do Curso Técnico em Informática Integrado ao Ensino Médio do Instituto Federal de Educação, Ciência e Tecnologia do Rio Grande do Sul (IFRS) - campus Farroupilha. O campus deu início a suas atividades em 2010 e a primeira turma de ensino médio ingressou no ano seguinte, o que faz dessa pesquisa a primeira investigação dos hábitos de leitura deste curso da instituição, estando com todas as turmas em andamento.

O instrumento de pesquisa utilizado foi um questionário de múltipla escolha, buscando atender os aspectos: gostos e visões sobre a leitura, razões pelas quais os alunos leem, preferências de entretenimento, influências para constituição de tal hábito (família, amigos, escola do ensino fundamental), auxílio da atual instituição no direcionamento pelo interesse do ato de ler e a relação com as redes sociais (o quanto elas influenciam nos hábitos de leitura).

Para a implementação do instrumento de pesquisa buscou-se utilizar uma plataforma interativa e de fácil acesso, a plataforma Google Forms. Além disso, tal método de aplicação relaciona-se com o uso de tecnologias como meio de facilitar distintos processos, englobando assim o aspecto tecnológico como instrumento de

\footnotetext{
2 Dados do TCC "Hábitos de leitura: uma pesquisa sobre as características da leitura entre os alunos do ensino médio/IFRS - campus Farroupilha”, da aluna Júlia Duarte Schenkel, trabalho que teve minha orientação.
} 
pesquisa. Optou-se pela aplicação através da internet devido ao número de entrevistados.

A aplicação do questionário foi realizada com todas as turmas, $1^{\circ}, 2^{\circ}, 3^{\circ}$ e $4^{\circ}$ ano, do curso Técnico em Informática Integrado ao Ensino Médio do IFRS - campus Farroupilha, resultando em um número de 105 alunos entrevistados. A fim de que todos os alunos do curso que compareceram à instituição no dia do ocorrido participassem da pesquisa, e levando em conta que o questionário a ser respondido estava disponível na internet, a aplicação se deu em um laboratório de informática da própria instituição durante o turno da tarde, período de aula dos estudantes, no segundo semestre de 2014.

O questionário foi respondido integralmente e individualmente pelos alunos, ou seja, em uma única vez foram respondidas todas as questões. Após preencherem todas as questões necessárias eles enviavam o questionário, fazendo com que as respostas fossem armazenadas automaticamente em uma tabela e que fosse gerado um novo questionário, idêntico, para ser respondido pelo próximo aluno que viesse ocupar o mesmo computador para a realização da tarefa.

Devido a sua extensão, que possibilitou uma análise detalhada e sob diversos aspectos, neste artigo será feito apenas um recorte, dividido em três partes: relação com a leitura; influências; e gostos e hábitos.

\section{Relação com a leitura}

Buscando compreender o que os alunos entendem como hábitos de leitura, a questão 1 evidenciou uma certa divisão de opiniões entre duas opções mais escolhidas. Em média $46 \%$ dos alunos entendem tal conceito como referente a todos os tipos de leitura pela qual se interessam e $43 \%$ entendem como a leitura de livros e textos literários. Há ainda cerca de $6 \%$ que consideram como significado a leitura de notícias e reportagens e $5 \%$ como a leitura de diversos textos como os das redes sociais. Ou seja, a leitura ainda está fortemente relacionada à leitura de livros em geral e obras literárias, já que $43 \%$ desconsideram a leitura em um amplo sentido, relacionando-a apenas à leitura literária.

Quando questionados sobre a visão que direcionam para a leitura, questão 2, a maioria, cerca de $98 \%$ dos alunos, relaciona a essa prática alguma das alternativas que a classificam como algo importante e de relevância em algum sentido. Dentre o percentual que a toma com relevância, aproximadamente $68 \%$ elegeu a alternativa que a define como essencial, tanto para a formação quanto para o entretenimento, sendo que em torno de $24 \%$ a definem como necessária e apenas $8 \%$ como algo interessante. Em relação às alternativas que não definem a prática dentro das classificações boas e úteis, percebe-se que menos de $2 \%$ dos jovens afirmam considerá-la algo desnecessário ou desinteressante.

Observando os dados obtidos por meio da questão 6, a qual levanta os motivos pelos quais os alunos costumam ler, há resultados muito positivos, já que $60 \%$ afirmam ler por iniciativa própria e por entretenimento, $22 \%$ dizem o fazer para entretenimento e por indicação de um amigo ou familiar e apenas $18 \%$ pontuam terem esse hábito apenas para a realização de trabalhos. Utilizando esses resultados, pode-se fazer uma relação com as informações apresentadas anteriormente e com o nível de interesse dos entrevistados pela leitura. Percebe-se, por exemplo, que todos os respondentes que dizem gostar muito ou gostar de ler possuem o hábito de ler para entretenimento e por iniciativa própria ou levando em conta a indicação de um amigo ou familiar, o que estabelece uma relação racional entre ambas, afinal é provável que quem goste da prática não a faça por mera obrigação. Já se for levado em conta os que dizem gostar em 
partes, pouco ou não gostar vê-se que 50\% afirmam praticar o ato da leitura apenas para a realização de trabalhos, ou seja, por obrigação.

Do mesmo modo, ao comparar os motivos pelos quais costumam ler (questão 6) com sua visão sobre tal prática (questão 2), ver-se-á que, por exemplo, os alunos que a consideram como algo desnecessário ou desinteressante leem apenas para trabalhos, ou seja, não por iniciativa própria. Já os que a consideram interessante, necessária ou essencial tanto para a formação quanto para o entretenimento, em $54 \%$ das vezes leem para entretenimento e por iniciativa própria ou por indicação e em $46 \%$ dos casos para a realização de trabalhos.

Analisando as considerações para com a relevância do ato de ler e comparandoas com as respostas representantes do nível de interesse, obtidas por meio da questão 3, pode-se perceber que há uma relação estável entre ambas, afinal cerca de $90 \%$ dos respondentes afirmam gostar de alguma maneira da prática em questão. Dentre esses $90 \%$ de maiores interesses, $28 \%$ afirmam gostar muito de leitura, 36\% dizem gostar e $25 \%$ gostam em partes, o que demonstra um nível de interesse alto para com o ato de ler visto que menos de $3 \%$ colocam a prática como algo totalmente externo aos seus gostos dizendo não gostar, tendo mais ou menos $7 \%$ afirmado gostar pouco.

Com base nos dados obtidos nessas duas questões percebemos que há, em geral, uma grande estabilidade entre ambas, já que a maioria dos entrevistados posiciona-se como quem gosta de leitura e a entende como algo importante. Tal dado é de suma relevância e contradiz a percepção generalizada de que os jovens não valorizam a leitura. As respostas que vão à contramão dessa visão foram pouco expressivas: apenas menos de $2 \%$ dos jovens consideram a leitura algo desnecessário ou desinteressante; em torno de 3\% afirmam não gostar de tal prática; e em média $7 \%$ dizem gostar pouco. Olhando por este ângulo, percebemos que, embora a maioria valorize e goste de ler, ainda há alguns que, mesmo entendendo a importância e considerando a leitura positivamente, não mantém interesse tão elevado pela prática. Essa característica também pode ser notada quando se analisam as atividades que os alunos preferem realizar no tempo livre, questão 5 , de modo que mesmo que no geral $36 \%$ afirmem gostar de ler e quase $29 \%$ gostar muito, a leitura de livros é a atividade preferida de apenas cerca de $22 \%$ e a de textos literários específicos de em média $3 \%$, sendo que o acesso às redes sociais ganha destaque com 47\%. Esses resultados remetem à ideia de que a leitura tem seu valor social consolidado, razão pela qual alguns alunos, mesmo não gostando ou gostando pouco da prática, a tem como essencial para sua formação, pois como afirma Zilberman (2015) "ideia, ideal e representação, a leitura se concretiza como uma prática, que se exerce individualmente, mas que resulta da concepção que a sociedade formula para as classes e as pessoas que a compõem.”.

Tais resultados vão ao encontro dos obtidos pela pesquisa "Retratos da leitura no Brasil", em que $85 \%$ dos participantes apontam como atividade favorita "assistir televisão", e apenas $28 \%$ citam "ler", no entanto quando questionados sobre o significado da leitura a consideram "fonte de conhecimento" (64\%) e leem por prazer (75\%) e com a motivação de atualização cultural (55\%) ou por gosto (49\%).

\section{Influências}

Martín-Barbero (1992) considera a mediação como uma espécie de estrutura incrustada nas práticas sociais cotidianas das pessoas, sendo que algumas mediações têm maior influência que outras, especialmente para os jovens. Dentre as principais influências com relação à prática de leitura, a pesquisa buscou verificar como ela 
ocorreu nas escolas em que cursaram o ensino fundamental, pelo acesso à internet e no ambiente familiar e círculo de amizades.

\subsection{Influência da escola no ensino fundamental}

Como a instituição de que os alunos que compõem a pesquisa fazem parte não oferta vagas para o ensino fundamental, é relevante analisar a influência que as escolas anteriores tiveram com relação à leitura. Do total, $74 \%$ dos alunos são oriundos exclusivamente de escolas públicas, $16 \%$ exclusivamente de escolas particulares e quase $10 \%$ cursaram parte do ensino fundamental em escola pública e parte em escola particular. Dentro desses percentuais podem ser feitas comparações relacionadas à visão e ao interesse pela leitura dos alunos de acordo com a rede escolar na qual cursou o ensino fundamental, para que assim possam ser observadas as possíveis características em comum para cada um dos três grupos. No entanto, ao analisar os dados fica claro que há certa paridade entre as escolas, já que, algumas apontam números mais altos em determinadas questões ao mesmo tempo em que contam com percentuais menores em outras.

Nota-se, por exemplo, que em torno de $65 \%$ dos jovens vindos de escola pública consideram a leitura algo essencial, tanto para a formação quanto para o entretenimento, $32 \%$ optam pelas opções que a descrevem como algo necessário ou interessante e apenas 3\% veem-na como desnecessária ou desinteressante. Deste ponto de vista podese afirmar que as escolas públicas cumprem com o papel de conscientizar os jovens quanto à importância do hábito de ler, no entanto apesar disso apenas $24 \%$ dizem gostar muito dessa prática, o que pode ser visto como um número relativamente baixo, enquanto a maioria afirma gostar $(38 \%)$ ou gostar em partes $(28 \%)$. Ao mesmo tempo, o baixo número de desinteresse destaca-se, já que menos de $2 \%$ colocam não gostar de ler e $7 \%$ gostar pouco. Se comparar esses dados com os dos alunos vindos de escolas particulares ver-se-á claramente pontos em que um grupo se favorece e outros em que o mesmo é desfavorecido. $\mathrm{O}$ fato de que $73 \%$ dos alunos oriundos de escolas particulares consideram a leitura algo essencial tanto para a formação quanto para o entretenimento e $27 \%$ define-a como necessária, classifica esse grupo com um percentual melhor em relação à visão para com a prática, de modo que não há a escolha de nenhuma resposta negativa como há no grupo anterior. Ainda assim, e embora apresente um maior percentual de alunos que dizem gostar muito de ler, sendo esse $34 \%$, o número cai em relação aos que gostam (25\%) e aumenta tanto nos que gostam em partes (28\%), gostam pouco (10\%) e não gostam (4\%), o que é algo que desfavorece. Para uma melhor compreensão das relações acima citadas, observe as Figuras 1 e 2. 


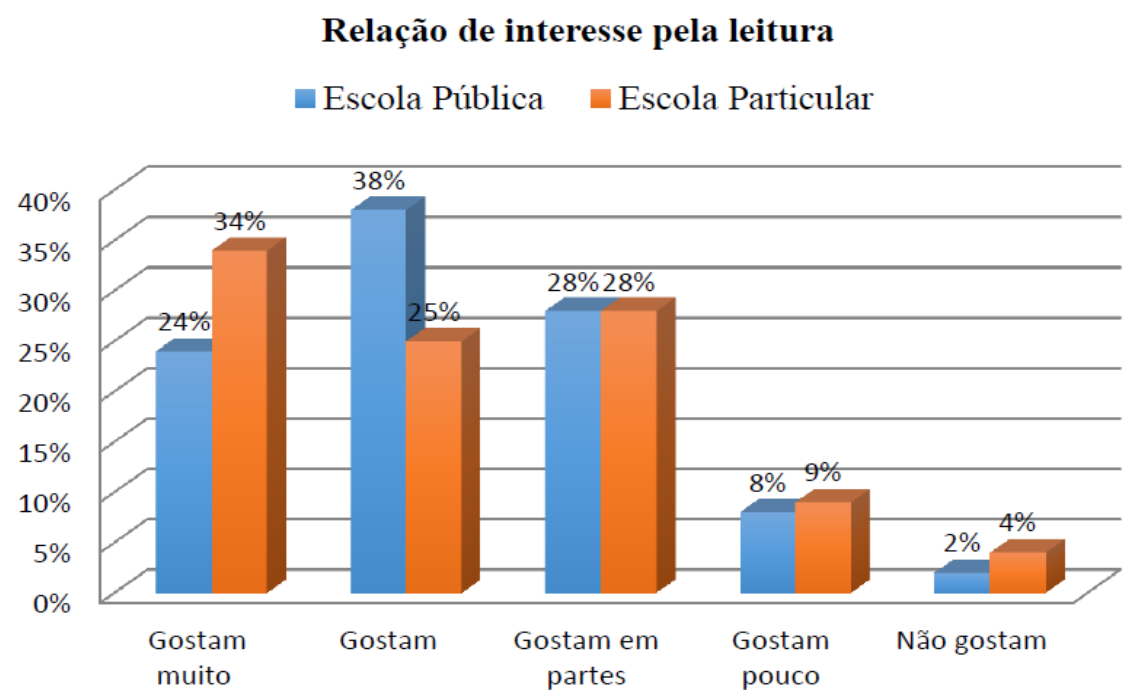

Figura 1: Interesse pela leitura $x$ Escola particular ou pública

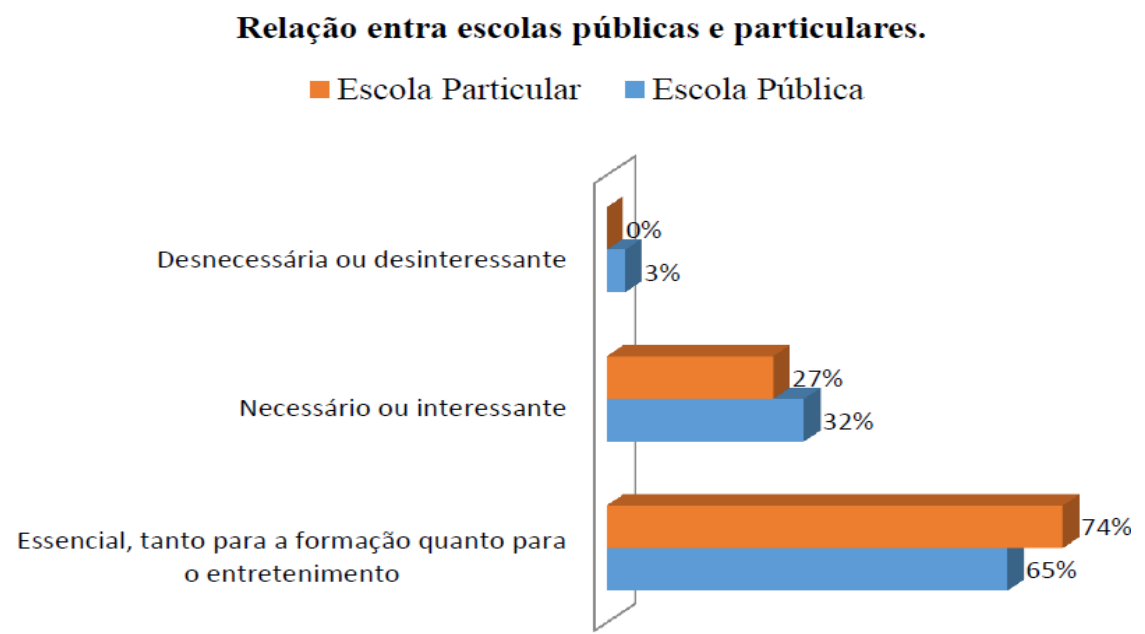

Figura 2: Visão da leitura x Escola particular ou pública

Há ainda um terceiro grupo, formado por alunos que cursaram parte do ensino fundamental em escola particular e parte em escola pública, o qual é o menor dentre os três. Neste, $70 \%$ veem a leitura como essencial, tanto para a formação quanto para o entretenimento, $20 \%$ como necessária e $10 \%$ como interessante, destacando-se a ausência de visões negativas, tal como no segundo grupo. Além disso, 50\% afirmam gostar muito de ler, enquanto $40 \%$ dizem gostar, dados que favorecem o grupo em relação aos anteriores, demonstrando que há equivalência entre a visão dos alunos para com esse hábito e o gosto pelo mesmo. No entanto, a porcentagem de mais ou menos $10 \%$ que afirmam não gostar de ler desfavorece-o em uma comparação com os demais. $\mathrm{O}$ fato de a atual instituição (IFRS) contar com um método seletivo de entrada faz com que a comparação em relação ao interesse desenvolvido nos alunos pelas antigas escolas seja pouco contrastante, a não ser pelas questões mais específicas, como as sobre a maneira como a leitura era incentivada nessas escolas, as quais permitem uma comparação independente dos entrevistados e de suas características estritamente pessoais. 


\subsection{Influências das redes sociais}

Os jovens estão sempre conectados a redes sociais e a aplicativos, através dos quais a comunicação se dá, primordialmente, através da leitura e da escrita. Assim sendo, muitos estudiosos, como Chartier (1999), atestam que os jovens leem muito mais do que a geração anterior, já que os meios digitais ampliam as possibilidades de leitura, afirmação que não encontra respaldo quando se busca tratar da qualidade dessa leitura. Para Silva (2009) e Araújo (2014) esse tipo de leitura contempla muita informação e pouca reflexão, além de resultar em contínuas "quebras", pois na internet somos levados de um link a outro - o que é positivo em termos de relações estabelecidas, mas acaba interrompendo o fluxo da leitura e dispersando o leitor.

Controvérsias a parte, é inegável que a internet possibilita o acesso a obras literárias, tanto por meio de sites legais de download gratuito, como o "Domínio Público", quanto ilegais. Junto a isso, há inúmeros blogs com resenhas de jovens recomendando ou não leituras, páginas no Facebook e inclusive videologs, alguns com uma montagem do enredo da história através de cenas de filmes, sites que listam obras já lidas com breves comentários, entre outros. Sem dúvida, os benefícios dentro desse meio existem, dentre eles o maior contato e interação direta como demonstra Silva quando coloca que

O leitor da era digital é leitor-autor; busca maior interação seja entre texto-leitor ou mesmo com outros pares, ainda que virtuais. Dialoga mais com o texto, ao "chamar" outros hipertextos a participarem de sua leitura; busca vídeos, clica em links, visita outros ambientes e interfere com comentários no que está lendo. Enfim, ele é muito mais participativo, tornando sua leitura mais significativa para si mesmo (SILVA, 2012, p.3).

Nas questões 15 e 16 há questionamentos sobre o quanto as redes sociais estimulam e influenciam a leitura. Pensando nessa relação dos jovens com as redes sociais pergunta-se na questão 15 se esses meios influenciam na escolha de novas leituras, sejam elas físicas ou virtuais, ao que a maioria $(25 \%)$ responde que isso acontece em partes. Além disso, 22\% dizem que essa influência ocorre geralmente e $20 \%$ dizem que é algo raro, sendo que as menores escolhas direcionam-se para as alternativas opostas "sim" (19\%) e "não" (14\%). Pode-se perceber também, por meio das respostas obtidas com a questão 16 , que em geral a maioria dos alunos, sendo esses pouco menos de $23 \%$, elege dentre as opções que exemplificam o quanto há um estímulo por parte das redes sociais, "geralmente" ou "em partes" havendo um empate sobre o quanto essas estimulam a leitura de acordo com o ciclo de amigos, através da apresentação de dicas de livros e textos literários.

Observando os resultados das duas questões fica evidente a relação entre ambas, já que há uma ligação lógica entre o percentual de escolha das alternativas das duas. Praticamente, a mesma maioria que afirma que as redes sociais influenciam em partes suas escolhas de leituras dizem que o estímulo por meio das mesmas também se dá em partes, o mesmo ocorre com todas as outras alternativas sendo que possuem resultados extremamente próximos e equivalentes no que diz respeito à influência e ao estímulo. Por exemplo, o percentual dos que dizem não haver influência (14\%) dos meios em questão e o dos que afirmam a ausência de estímulo (15\%) são muito próximos, bem como os que dizem haver a influência e os que afirmam receberem estímulo que contam com o mesmo percentual (19\%). Possivelmente tal relação deve-se ao fato de que, 
automaticamente, as pessoas que assumem serem estimuladas à leitura pelas redes sociais concordam que esse é um meio que as influencia, ou seja, a visão para com a influência adequa-se de acordo com a visão de recepção, ou não, de estímulo. Afinal, é lógico aqueles que dizem serem estimulados assumirem serem influenciados, já que se não fossem não haveria como receberem estímulo, o mesmo enquadra-se a todas as outras alternativas que completam-se, de modo que o mesmo ocorre com os que colocam não serem influenciados ou estimulados.

Analisando a relação do estímulo dessas redes com os gostos percebe-se que dentre os que dizem gostar muito ou gostar de ler, a opção mais escolhida para definir este nível de estímulo diz que sim (28\%), as redes sociais estimulam a leitura por meio de dicas, sendo que $25 \%$ dizem que geralmente isso acontece e apenas $9 \%$ dizem que não, sendo que os demais se dividem entre as outras opções. Já dentre os que afirmam gostar em partes de ler, $35 \%$ dizem que esse estímulo ocorre em partes e $29 \%$ dizem que acontece raramente, de modo que cerca de $10 \%$ dizem que não ocorre e o restante opta pelas outras alternativas. Em relação a quem gosta pouco ou não gosta, ganha destaque a escolha pela opção que afirma que este meio não estimula o hábito, tendo em torno de $35 \%$ das escolhas seguido por $25 \%$ da opção raramente. Com base nesses dados, evidencia-se uma característica um tanto quanto particular deste meio que, ao contrário dos demais agentes estimuladores, leva fortemente em conta a interesse de cada indivíduo para determinados assuntos e costumes. Ou seja, este meio adapta-se de acordo com as preferências que definem os ciclos de relacionamento, de modo que cada um possui maiores contatos, como páginas curtidas e amigos de gostos próximos, relacionados ao que lhe atrai. Sendo assim, como demonstram os dados citados acima, conforme o nível de interesse pelo hábito de leitura diminui, a visão sobre o quanto este meio estimula tal prática diminui também acompanhando tal característica que define a estrutura dessas redes.

\subsection{Influência dos pais e dos amigos}

A família e os amigos estabelecem-se como um exemplo de que a leitura constitui-se sobre inúmeras peculiaridades previamente vigentes em círculos específicos de relações e não se define como algo natural e independente de exterioridades. Afinal a conduta, os pensamentos e os hábitos daqueles com os quais se convive incidem diretamente na formação pessoal direcionando muitas das características e costumes. Deste modo, tem-se que em uma família ou grupo de amigos em que o ato de ler é incentivado, e ainda mais se praticado, serão formados leitores com um hábito de leitura maior do que se, provavelmente, comparado com o leitor de uma família, ou círculo de amigos, em que o ato não é estimulado ou praticado. "Quanto mais cedo se inicia o processo de aprendizagem de leitura, mais chances terá o futuro cidadão de nunca abandonar o hábito de leitura." (MORO et al., s.d., p.4). A afirmação de Moro deixa clara a influência do estímulo para o hábito de leitura, de modo que a participação dos familiares na formação da criança eleva as chances de que ela adote um hábito de leitura regular e que a acompanhará, provavelmente, ao longo da vida. Assim sendo "a criança que sempre tiver ao seu alcance um livro e souber lê-lo proveitosamente, dificilmente irá procurar os sites que oferecem os resumos das obras literárias. Certamente, quando adolescente, saberá distinguir a leitura de boa da de má qualidade" (MORO et al., s.d., p.4). Sendo assim, a responsabilidade pela formação do leitor estende-se também à família, de modo que a característica de estímulo difere fortemente a formação da personalidade e dos interesses de cada indivíduo. 
Tais pressupostos foram averiguados por meio de uma série de questões. Quando indagados, por meio da questão 17, sobre o costume que os pais conservam quanto à leitura, a maior parte afirma que os pais costumam ler, sendo que há praticamente um empate entre as alternativas que dizem que leem frequentemente (34\%) e leem algumas vezes (35\%) já que a diferença é de apenas $1 \%$. De modo que há ainda $22 \%$ que afirmam que os pais costumam ler poucas vezes, sendo que a alternativa de menor escolha conta com apenas cerca de $8 \%$ dos respondentes e diz respeito aos pais que, segundo os filhos, nunca leem. Dentre esses pais que costumam ler, observa-se que a maioria, cerca de $52 \%$, costuma ler textos disponíveis em revistas ou jornais e ainda, resultando em um quase empate, $48 \%$ costumam ler livros. Além disso, vale ressaltar que $0 \%$ dos pais mantém o hábito de ler textos nas redes sociais, o que provavelmente se deva ao fato de esse ser um meio não há muito introduzido de modo que, mesmo com a grande migração de distintos públicos, aparentemente os jovens são mais próximos, ou então não se dão conta dos hábitos dos pais quanto às redes sociais.

O posicionamento dos pais quanto à leitura está relacionado ao seu nível de escolaridade. Nota-se que dentre os pais que leem frequentemente ou algumas vezes a maioria das mães, $20 \%$, possuem pós-graduação ou ensino médio completo, sendo que $19 \%$ possuem ensino superior completo e a maioria dos pais, $24 \%$, possuem ensino médio completo sendo que $19 \%$ iniciaram o ensino superior e não o concluíram. Já entre os pais que costumam ler poucas vezes ou não leem, destacam-se mães com ensino médio completo, sendo essas $33 \%$, ou com ensino fundamental incompleto, $27 \%$, e pais que também possuem ensino fundamental incompleto, 27\%, ou ainda ensino médio completo, sendo esses $24 \%$.

Por meio desses dados comparativos é possível notar o quanto a escola possui um papel importante, pois os pais com maior presença no âmbito educacional aderem a uma relação mais direta com determinadas práticas como a leitura, já que essa é parte inseparável deste meio e além de que muitas vezes os que não constroem uma relação tão próxima com a formação possuem outras prioridades ou necessidades que os direcionam a constituição mais intensa de outros hábitos. Tal característica fica evidente, já que dentre os pais com o costume de ler frequentemente ou algumas vezes muitos possuem ensino superior ou pós-graduação, enquanto que dentre os pais que não costumam ler muito frequentemente ou até mesmo nunca leem a maioria conta ou com o ensino médio completo ou até mesmo com o ensino fundamental incompleto.

Levando em conta ainda as respostas referentes à prática de leitura pelos pais, pode ser feito um paralelo com a questão 20, a qual diz respeito ao quanto os pais incentivam o hábito da leitura. Em torno de $66 \%$ dos alunos afirmam que os pais os incentivam a ler e $28 \%$ dizem que incentivam um pouco, o que resultam dados bastante positivos ainda mais se somados ao fato de que apenas cerca de $6 \%$ dizem que os pais não incentivam. A maneira como se dá o incentivo em $34 \%$ dos casos é através da compra de livros, sendo que em seguida há um empate entre o incentivo por intermédio da sugestão de leitura e pela solicitação para que os filhos leiam com $25 \%$ das respostas. Além disso, mesmo que $34 \%$ dos pais leiam frequentemente, o método de ler para dar o exemplo ficou em último lugar com 17\% das escolhas. A Fig. 3 mostra os percentuais referentes ao incentivo por parte dos pais e a quantidade de alunos que selecionaram cada uma das opções referente à maneira como se dá esse incentivo. 
20. Seus pais incentivam você a

ler?

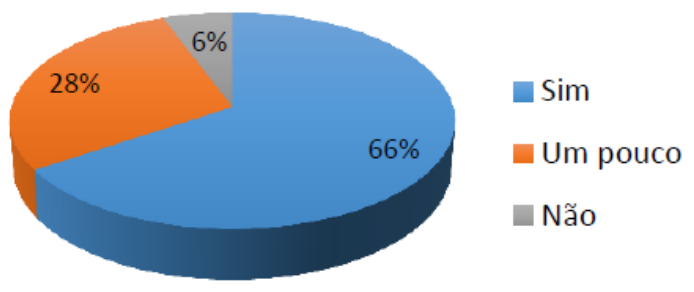

Figura 3: Incentivo pelos pais

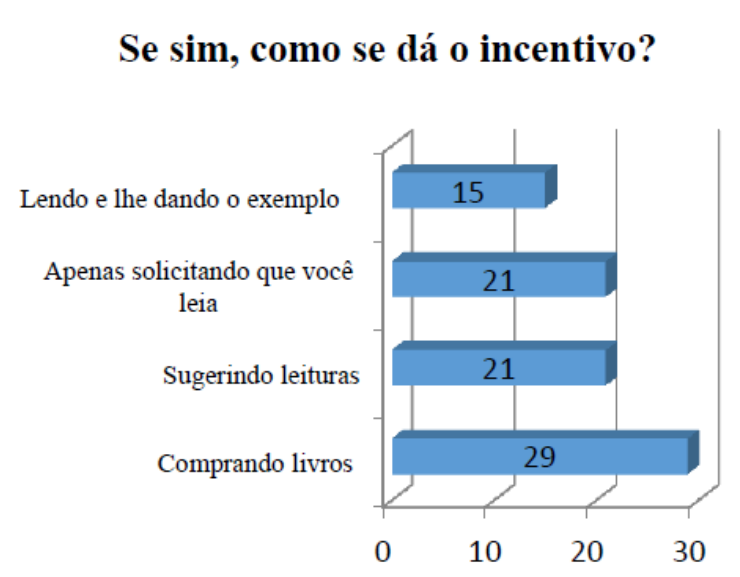

Em uma comparação entre as respostas referentes ao hábito de leitura dos pais e ao incentivo a partir dos mesmos, percebe-se que dentre os pais que costumam ler frequentemente ou ler algumas vezes $75 \%$ estimulam os filhos a ler e menos de $3 \%$ não o fazem, de modo que dentre os que leem pouco ou não leem $40 \%$ estimulam e $13 \%$ não. Com base nisso comprova-se que as pessoas que mantém o hábito de ler tendem a influenciar mais positivamente outros que com elas convivem, ou seja, exercem um maior incentivo, no entanto constata-se também que mesmo no grupo de pais que não costumam ler, muito embora o número da ausência de incentivo tenha crescido se comparado ao anterior, ainda há a presença de incentivo predominantemente.

Em relação à influência da escolaridade sobre o quanto os pais incentivam os filhos a lerem, percebe-se que entre os pais que costumam estimular esse hábito a maioria das mães, $23 \%$, possuem ensino médio completo ou ainda $22 \%$ pós graduação, sendo que $26 \%$ dos pais possuem ensino médio completo ou ainda $19 \%$ ensino superior incompleto. Fica perceptível por meio disso que os pais com maior escolaridade tendem ao incentivo, no entanto nota-se também que na questão de incentivo mesmo os pais com escolaridade mais baixa costumam incentivar seus filhos quanto à leitura, já que, como exposto anteriormente, apenas $6 \%$ dos alunos dizem não serem incentivados. Além de que essa ausência não se restringe aos de menor escolaridade já que correspondem desde pais de ensino fundamental incompleto até alguns com pósgraduação.

Relativo à influência por parte dos pais tem-se ainda a questão 19, a qual indaga os alunos quanto à frequência com que os pais costumavam ler para eles quando eram crianças. Tal iniciativa para com crianças tende a incentivar o ato da leitura, já que insere desde cedo o hábito no cotidiano das mesmas e faz com que iniciem o amadurecimento de seus gostos quanto a essa prática, afinal de contas, como coloca Moro (et al., s.d, p.4), quanto mais cedo forem iniciados no processo da leitura menores serão as chances de abandonarem esse hábito.

Para classificar a frequência de leitura dos pais para os filhos, a maioria das respostas concentrou-se na alternativa "algumas vezes" que obteve $35 \%$ das escolhas, seguida pela opção "frequentemente" (28\%), "raramente" $(15 \%)$ e por último, no entanto com um percentual não muito baixo, "nunca" (22\%). Observando as respostas dessa questão e relacionando-as com o nível de interesse dos alunos pela leitura, ilustrado na Fig. 4, percebe-se que, dentre os alunos que afirmam terem os pais lido para eles com frequência ou algumas vezes 35\% dizem gostar de ler e 32\% gostar muito, sendo que apenas cerca de $5 \%$ dizem gostar pouco e em torno de $1 \%$ afirmam não 
gostar. Já os alunos com pais que liam para eles raramente ou nunca, apesar de $37 \%$ dizerem gostar de ler, o número dos que gostam pouco e que não gostam eleva-se, sendo esses $10 \%$ e $5 \%$ respectivamente, bem como o número dos que gostam muito também diminui indo para $22 \%$.

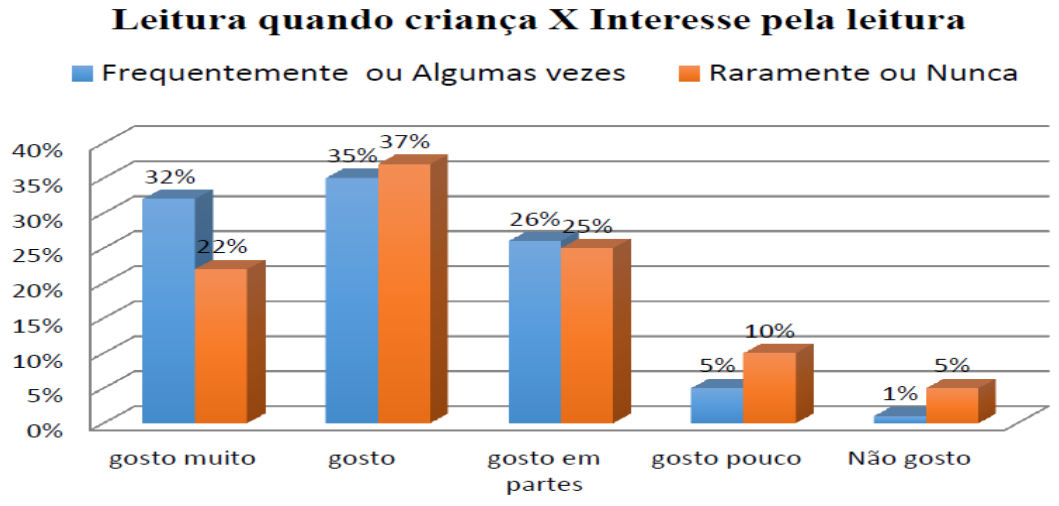

Figura 4: Leitura para crianças e interesse

Dentro das influências direcionadas pelos grupos de convívio, além dos pais podem ser citados os amigos como inclusos na lista de influências diretas. Percebe-se por meio da questão 18 que $48 \%$ dos alunos, a maioria, dizem que seus amigos costumam ler, sejam livros, revistas ou jornais, algumas vezes, de modo que $36 \%$ dizem que leem frequentemente. Analisando por este ponto percebe-se que tais dados podem ser um tanto quanto positivos, já que a maior parte diz conviver com grupos de amigos que leem, sendo que apenas cerca de $4 \%$ dizem que os amigos nunca leem. Com base nisso é possível a comparação dessas respostas com o quanto os alunos se interessam pela leitura, de modo que tal comparação permite observar o quanto se dá a influência por meio desses agentes. Nota-se que dentro do grupo de alunos optantes pelas alternativas que colocam os amigos como sendo pessoas que leem frequentemente ou algumas vezes, $36 \%$ dizem gostar de ler e $32 \%$ gostar muito, o que demonstra um nível alto de interesse para com a leitura sendo que pouco menos de $3 \%$ dizem não gostar dessa prática. Já dentre os que colocam os amigos como quem lê raramente ou nunca, $35 \%$ diz gostar ou gostar em partes e nenhum afirma gostar muito. Deste modo a influência dos interesses de pessoas próximas como os amigos fica evidente, sendo que há uma relação lógica entre as respostas, ou seja, os que possuem amigos mais ligados com a leitura aparentam interessar-se mais pela mesma, bem como os que contam com amigos não muito interessados pela prática também apresentam um interesse menor.

\section{Gostos e hábitos}

Em relação aos gostos dos alunos entrevistados, percebe-se, através das respostas obtidas por meio da pergunta 4, quais são os gêneros de maior e menor interesse dos alunos. As respostas contabilizadas podem ser observadas na Fig. 5, na qual se baseiam as análises sobre as preferências dos alunos que serão apresentadas na sequência.

De acordo com os dados dessa questão, percebe-se que a maior parte dos alunos apresenta um grande interesse pelos gêneros aventura e séries/trilogias, de modo que $81 \%$ dos entrevistados selecionaram as opções que representam maior interesse em relação ao suspense, sendo $42 \%$ "Gosto muito" e 38\% "Gosto", e 72\% selecionaram as 
opções de mesmo nível para as séries e trilogias, sendo 44\% "Gosto muito" e 28\% "Gosto". Além disso, esses dois gêneros, aventura $(3,8 \%)$ e séries $(4,7 \%)$, junto ao suspense $(3,8 \%)$ e contos $(4,7 \%)$ estão entre os que possuem menor número de escolha da alternativa "não gosto", depois apenas de romance, o qual não obteve nenhuma escolha da alternativa em questão.

\section{3- Gostos pela leitura}

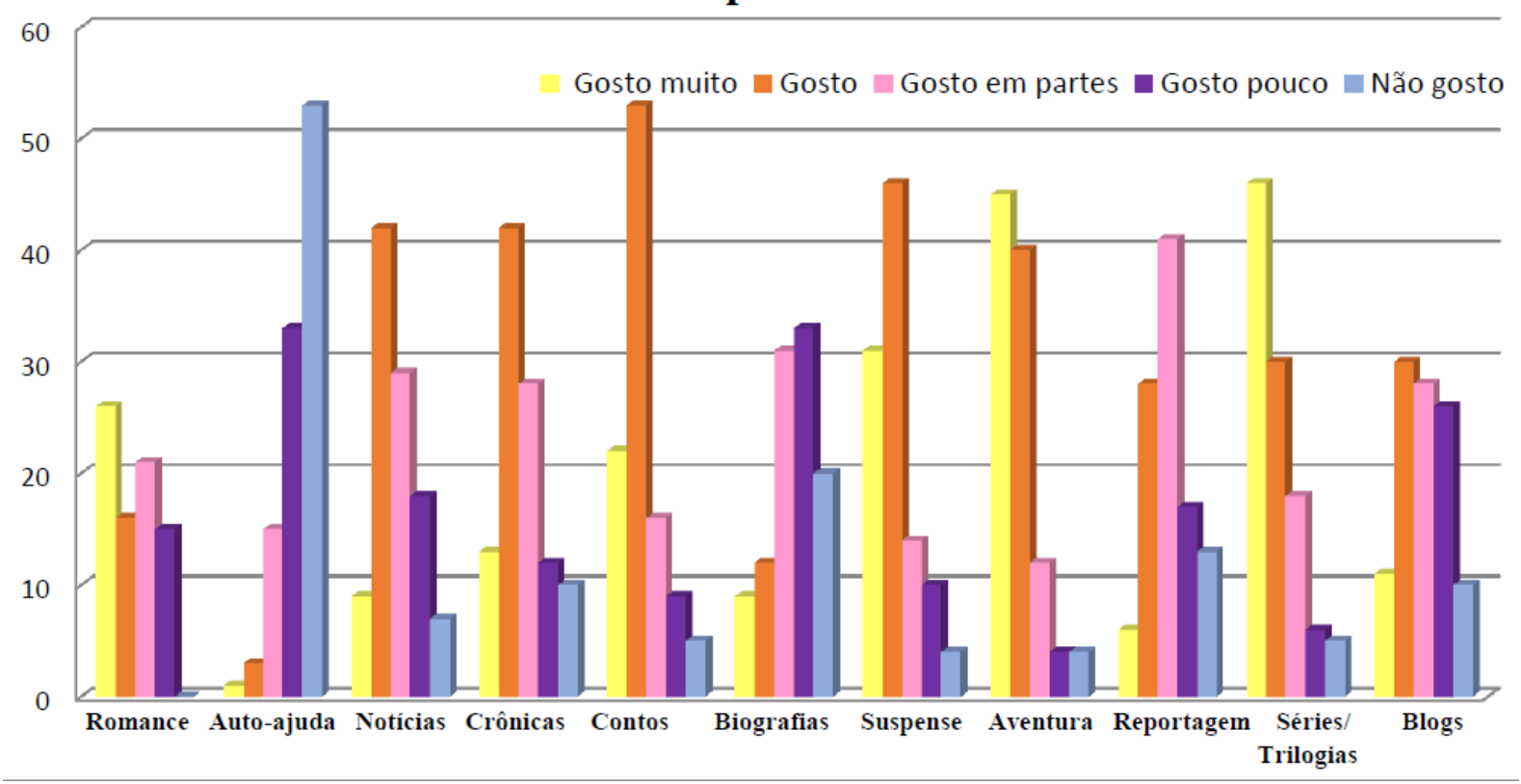

Figura 5: Gostos dos alunos - gêneros textuais

O gênero suspense, já citado anteriormente, também obteve uma boa qualificação segundo o interesse dos alunos, de modo a classificar-se como o terceiro com maior nível de interesse se levado em conta o número de escolhas da alternativa "Gosto muito" (29,52\%), tendo obtido 43,8\% de escolhas na opção "Gosto", o que equivale a mais ou menos $73 \%$ de escolhas direcionadas a uma dessas duas opções. $\mathrm{O}$ romance, como já foi dito, destacou-se pelo fato de ser o único a ter a alternativa "Não gosto" sem nenhuma escolha, apesar de contar com 14,28\% de escolhas direcionadas à alternativa "Gosto pouco" o que se sobressai aos gêneros anteriores (aventura: 3,8\%, séries: $6,7 \%$ e suspense: 9,5\%), sendo que se coloca logo depois do suspense se observada a alternativa "Gosto muito" na qual recebeu 24,76\% das respostas, sendo seguida por $20 \%$ de escolhas para "Gosto em partes". Observando as respostas relacionadas ao gênero dos contos percebe-se que a maior parte das escolhas acumula-se na alternativa "Gosto" a qual conta com aproximadamente $50 \%$ das escolhas, sendo que a alternativa "Gosto muito" foi escolhida por em torno de $20 \%$ dos entrevistados.

Observa-se ainda que as crônicas com a escolha das opções concentradas nas alternativas "Gosto" 40\% e "Gosto em partes" 26,7\%, assim como as notícias que também tiveram as respostas concentradas nessas duas alternativas $(40 \%)$ e $(27,6 \%)$ respectivamente, sendo que o número de escolhas direcionado a alternativa que representa a ausência de interesse ("Não gosto") neste segundo gênero apresenta-se consideravelmente baixa, em torno de $6 \%$, como as dos gêneros citados até aqui. $\mathrm{O}$ mesmo acontece com as reportagens e com os textos de blog, nos quais as opções "Gosto" (Reportagem: 26,6\% e Blogs: 28,6\%) e "Gosto em partes" (Reportagem: 39\% e Blogs: 26,7\%) são mais escolhidas, entretanto nessa a opção que representa menor interesse, se levadas em conta essas duas opções, aparece mais elevada do que a anterior. 
Seguindo essa linha, percebemos que dentro das opções de gêneros disponíveis, os citados anteriormente foram os quais receberam uma concentração de resposta que variou entre as três primeiras alternativas (Gosto muito, Gosto, Gosto em partes) como as com maior número de escolhas, ou seja, dentre os gêneros literários sugeridos esses foram os que se destacaram nos gostos dos alunos. Vale ressaltar que os que tiveram uma maior concentração nas duas primeiras opções foram aventuras, séries e suspenses, além do conto que também teve as duas opções como as mais optadas, sendo elas 50,5\% "Gosto" e 19\% "Gosto muito". Apesar de não ter tido uma concentração de respostas entre as duas primeiras alternativas, os romances contam com a vantagem de, como já foi colocado, ser o único em que não houve nenhum entrevistado que o colocasse como totalmente fora de seus gostos, ou seja, ninguém optou pela alternativa "Não gosto" quanto a esse gênero.

Além dos gêneros apresentados anteriormente, os entrevistados ainda foram questionados quanto o interesse para com outros dois, os quais obtiveram uma concentração de escolhas que não esteve entre as três primeiras alternativas. Um desses dois gêneros, sendo ele as biografias obtiveram maior concentração nas alternativas "Gosto em partes" (29,5\%) e "Gosto pouco" (31,4\%), o que demonstra um interesse que não está entre os mais altos mas também não entre os mais baixos. $\mathrm{O}$ outro gênero apresentado foi o autoajuda, o qual obteve o menor nível de interesse por parte dos entrevistados, visto que a concentração das respostas se deu nas duas últimas alternativas ("Gosto pouco" e "Não gosto"). Esse recebeu 50,5\% das escolhas na última alternativa, a qual representa a ausência de interesse, e 31,4\% na alternativa "Gosto pouco", sendo que a primeira alternativa ("Gosto muito") obteve menos de 1\% das escolhas.

Levando em conta as respostas obtidas por meio dessa questão os gostos dos jovens ficam evidentes e percebe-se que o maior interesse refere-se principalmente aos gêneros de entretenimento. Embora haja interesses diversificados, a maioria está concentrada na literatura direcionada ao público adolescente que, na maioria das vezes, são pertencentes aos gêneros aventura, suspense, romance ou formam aclamadas séries ou trilogias. Tal característica é detectada também através da questão 25, a qual questiona os entrevistados sobre a existência, ou não, de um livro que tenha marcado suas vidas, para a qual as respostas oscilam principalmente entre esses gêneros.

Em geral, os livros citados, principalmente os que se repetem, possuem como característica em comum o fato de serem de sucesso ou até considerados best-sellers. Tal característica referente ao gosto por livros um tanto quanto midiáticos é algo comum, principalmente entre os jovens, já que as obras de sucesso são altamente difundidas e, de acordo com Araujo (2014), basicamente seguem um padrão que conduz à recepção do público e ao sucesso. Seguindo nessa linha, a autora coloca que o leitor de best-seller quer conteúdo interessante e não forma rebuscada de escrita, com palavras simples e em um texto bem direto, que flua sem que o leitor precise parar para pensar, o que remete ao fato de muitos dos livros famosos apresentarem histórias semelhantes e seguirem alguns padrões. Isso acontece, por exemplo, quando é afirmado que os alunos em geral gostam do gênero romance e por meio da colocação dos livros percebe-se que os romances referidos condizem aos mais atuais, de fácil compreensão e estrutura semelhante e um tanto quanto padronizada, em que se enquadram sucessos como "A última música", de Nicholas Sparks, e "A culpa é das estrelas", de John Green.

Apesar dessa predominância, é observada também a presença de leituras mais densas e que exigem maior interação e reflexão por parte de seus leitores, como é o caso do clássico da literatura brasileira "O continente", de Erico Veríssimo, e ainda de outras obras extensas como "Senhor dos anéis", de J.R.R. Tolkien. Com isso, apresenta-se a 
questão de os gostos, apesar de muitos semelhantes, serem diferenciados, ao menos em alguns pontos, levando em conta uma série de características específicas que incidem sobre isso, como os grupos de convívio, trajetória de leitura anterior, faixa etária e gênero. Já que, por exemplo, percebe-se que são meninas que colocam os romances padrões da atualidade dentre a lista de preferências, e que esses, em geral, são especialmente direcionados ao público jovem.

Ainda sobre os hábitos de leitura dos alunos, por meio dos dados das questões 7 , 8 e 9 é possível inteirar-se um pouco mais sobre as características que os compõem, já que essas questões disponibilizam três vertentes de leitura para saber qual é a relação dos respondentes com as mesmas. Segundo as respostas obtidas nessas questões, a maior parte dos alunos elegeu as opções que indicam que 39\%, a maioria dos alunos, costumam ler jornais ou revistas semanalmente sendo que $26 \%$ dizem ler mensalmente e $22 \%$ diariamente. Em relação à leitura de livros, $27 \%$ dizem que o fazem mensalmente sendo seguido por $23 \%$ que dizem ler semanalmente e $19 \%$ diariamente. Já quanto à leitura de textos disponíveis nas redes sociais, há uma concentração apenas em duas opções, sendo que 53\% dizem lê-los diariamente e 35\% semanalmente.

Ao comparar os dados obtidos por meio dessas questões nota-se que habitualmente os jovens, em sua grande maioria, interagem cotidianamente com textos de redes sociais, sendo que a diferença nos números relacionados à leitura diária é gritante deixando esse meio bem acima dos demais. Percebe-se também que os livros são o tipo de leitura que é menos lido diariamente e que contam com o maior percentual de leitura em um maior prazo como o trimestral $(14 \%)$ ou anual $(17 \%)$. Constata-se por meio disso que essa possivelmente é uma característica dos adolescentes, o que se pode perceber ao comparar esses resultados com quais tipos de leitura os pais costumam fazer (questão 7.1) já que para esses os textos em redes sociais não são relatados nenhuma vez. Com base nisso afirma-se que os jovens mantêm como hábito principalmente as interações mais rápidas e fáceis, como é o caso da leitura de textos pelo acesso às redes o que, provavelmente, já se tornou algo automático. Tal característica é novamente verificada quando, na questão $14,37 \%$ dos alunos assumem serem um pouco influenciados pelas redes sociais no quanto leem externamente a essas. Apesar disso, há um grande número que discordam dessa influência já que em torno de $29 \%$ dizem quase não serem influenciados por esse meio e $27 \%$ discordarem totalmente disso afirmando que as redes não interferem em nada.

Ainda analisando as prováveis relações dos alunos com as redes sociais, observam-se os resultados das questões 11,12 e 13, os quais tratam da interação e utilização dos textos disponíveis nesse meio e serão abordados a seguir.

Sabe-se que esse é um meio que dispõe uma grande quantidade de conteúdos distintos ao mesmo tempo, sendo que os apresenta de forma direta ou disponibilizando links que ao serem selecionados direcionam os leitores para determinados textos e assuntos. Tendo em conta isso e buscando entender melhor a relação dos usuários com essa dinâmica, a questão 11 questiona o costume de averiguar os links disponíveis nessas redes, ao que se percebe que a maioria, 33\%, afirmam que geralmente abrem esses links e, como quase um empate, em torno de $32 \%$ dizem fazê-lo em partes, sendo que apenas $2 \%$ dizem não abrir. Para entender melhor o que tais textos disponíveis nesse meio significam para os alunos, as repostas anteriores podem ser relacionadas com as obtidas pela questão 12, a qual questiona a qualidade desses textos. Para essa pergunta, em média $40 \%$ dos respondentes dizem que tais textos acrescentam em partes algo a suas bagagens intelectuais, sendo que há uma variação de visões quando $26 \%$ dizem que geralmente acrescentam e $20 \%$ que raramente isso acontece.

Quando questionados sobre a característica de extrema diversidade das redes 
sociais, ou seja, a abordagem de distintos assuntos de maneira paralela, algumas alternativas contam com a concentração das respostas como pode ser visto no gráfico apresentado anteriormente. A maioria, em torno de 35\%, diz que as redes sociais direcionam a realização de leituras quebradas em parte das vezes e $32 \%$ dizem que isso acontece geralmente, ou seja, evidencia-se a característica de dinamismo em que os leitores passam de um texto para outro sem, na maior parte das vezes, aprofundar um assunto específico. Com base nisso percebe-se a provável baixa densidade das leituras desse meio, de modo que em suas curtas extensões geralmente não apresentam uma maior reflexão, mas sim, como já foi colocado anteriormente, leituras automáticas. Essa característica provavelmente pode influenciar na relação dos usuários com outros tipos de leitura, já que podem habituar-se a realizar apenas esse estilo de leitura mais facilitado. Tal fato liga-se com a questão 10, a qual aborda com que frequência os alunos realizam a leitura de livros completos. No entanto as respostas dessa questão contradizem essa provável influência, já que a maioria, $42 \%$, afirma ler até o final e $37 \%$ geralmente concluir a leitura, sendo que nenhum diz nunca acabá-la.

\section{Considerações finais}

A partir das análises apresentadas, percebe-se que o desafio do professor de literatura é levar seus alunos à prática de leitura literária, pois o público constitui-se em jovens que gostam de ler - com 64\% afirmando gostar muito ou gostar de ler -, que leem por iniciativa própria e por entretenimento $(60 \%)$ e, em sua esmagadora maioria (98\%), que atribuem valores positivos à leitura, considerando-a uma prática importante.

No entanto, quando averiguadas suas obras favoritas, houve apenas uma citação de obra pertencente ao cânone literário. Assim mesmo, tal dado não pode ser considerado como negativo, já que dentre os gêneros favoritos encontram-se o romance, além de contos, e também pelo fato de que entre os gêneros aos quais atribuíram visão negativa a única opção que se destacou foi o de autoajuda.

Diante desse perfil fica claro que o desafio é levar tais alunos à leitura literária, deixando de lado a visão generalista de que os alunos não leem ou não gostam de ler, discurso predominante no ambiente escolar. E tal desafio pode contar com o auxílio da influência da internet e seu uso constante. É importante aceitar a presença dos meios digitais no cotidiano dos adolescentes e instrumentalizá-los para o uso do ambiente digital como ferramenta positiva para a leitura, seja através da indicação de sites ou aplicativos de leitura ou utilizando os recursos digitais em ações que integrem a literatura.

Em suma, os resultados aqui apresentados podem ser utilizados para direcionar práticas significativas para o fomento à leitura literária dos alunos. É fundamental que as instituições conheçam as visões e posicionamentos dos alunos sobre a leitura, para que possam atuar da melhor maneira mediando-a e fomentando-a, buscando que os jovens não se restrinjam ao entendimento do valor da leitura, mas que estendam tal consciência à prática cotidiana.

\section{Referências}

ARAÚJO, Felipe. "Facebook.com: o (multi)letramento das gerações pós-modernas nas habilidades de leitura e escrita". Revista Eletrônica de Letras (Online), v.7, p. 1-42, janeiro-dezembro, 2014. 
ARAUJO, Mayara Regina Pereira Dau. "Leitores de Best-sellers: o que determina suas escolhas?" In: III Colóquio internacional de estudos linguísticos e literários. Maringá, 2014. Anais Eletrônicos. Programa de Pós-graduação em Letras. Disponível em http://cielli2014.com.br/media/doc/a2575b99167aac260eec5b39b19d2319.pdf. Acesso em: 10 ago. 2015.

BRASIL, SEF. Parâmetros Curriculares Nacionais: Língua Portuguesa: Ensino Médio. Brasília: SEF, 1998.

CHARTIER, Roger. A aventura do livro: do leitor ao navegador. 2ed. São Paulo: UNESP/ Imprensa Oficial do Estado, 1999.

ECO, Umberto. Interpretação e superinterpretação. São Paulo: Martins Fontes, 1993. "Sobre algumas funções da literatura". In: Sobre a literatura. 2.ed. Rio de Janeiro: Record, 2003.

MARTÍN-BARBERO, Jesús y MUÑOZ Sonia (orgs). Televisión y Melodrama. Bogotá: Tecer Mundo Editores. 1992.

MORO, Eliane L. da Silva; SOUTO, Gabriela Pinheiro; ESTABEL, Lizandra Brasil. A influência da internet nos hábitos de leitura do adolescentes. s.d.,13f.

Retratos da leitura no Brasil. 3. ed. Instituto Pró-Livro. 2014. Disponível em <http://prolivro.org.br/home/images/relatorios_boletins/3_ed_pesquisa_retratos_leitura IPL.pdf>. Acesso em 30 jul. 2015.

SILVA, Ezequiel Theodoro. Criticidade e leitura: ensaios. São Paulo: Global, 2009.

SILVA, Solimar Patriota. O Facebook na formação continuada de mediadores de leitura. Rio de Janeiro, 2012. $10 \mathrm{f}$.

SOLÉ, Isabel. Estratégias de leitura. 6.ed. São Paulo: Artmed, 1998.

ZILBERMAN, Regina. A leitura no Brasil: sua história e suas instituições. Disponível em <http://www.unicamp.br/iel/memoria/projetos/ensaios/ensaio32.html >. Acesso em 30 jul. 2015. 